\title{
Belgeo
}

Revue belge de géographie

\section{Paleo-ecologisch onderzoek van een Holocene sequentie uit het Deurganckdok te Doel (Wase Scheldepolders, Noord-België)}

Palaeo-ecological study of a holocene sequence from the deurganckdok at doel (lower scheldt polders, northern belgium)

Vanessa Gelorini, Lieselotte Meersschaert, Elie Verleyen et Cyriel Verbruggen

\section{(2) OpenEdition}

\section{Journals}

Édition électronique

URL : http://journals.openedition.org/belgeo/11999

DOI : 10.4000/belgeo.11999

ISSN : 2294-9135

Éditeur :

National Committee of Geography of Belgium, Société Royale Belge de Géographie

Édition imprimée

Date de publication : 30 septembre 2006

Pagination : 243-264

ISSN : 1377-2368

Référence électronique

Vanessa Gelorini, Lieselotte Meersschaert, Elie Verleyen en Cyriel Verbruggen, «Paleo-ecologisch onderzoek van een Holocene sequentie uit het Deurganckdok te Doel (Wase Scheldepolders, NoordBelgië) », Belgeo [Online], 3 | 2006, Online op 30 octobre 2013, geraadpleegd op 19 avril 2019. URL : http://journals.openedition.org/belgeo/11999; DOI : 10.4000/belgeo.11999

Ce document a été généré automatiquement le 19 avril 2019.

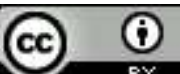

Belgeo est mis à disposition selon les termes de la licence Creative Commons Attribution 4.0 International. 


\title{
Paleo-ecologisch onderzoek van een Holocene sequentie uit het Deurganckdok te Doel (Wase Scheldepolders, Noord-België)
}

\author{
Palaeo-ecological study of a holocene sequence from the deurganckdok at doel \\ (lower scheldt polders, northern belgium)
}

Vanessa Gelorini, Lieselotte Meersschaert, Elie Verleyen et Cyriel Verbruggen

\section{Inleiding}

1 Tijdens graafwerken voor de aanleg van het Deurganckdok in het Antwerpse havengebied op de linker Scheldeoever werden over een grote afstand en tot op een grote diepte Holocene afzettingen aangesneden. Een organische sequentie werd voor paleobotanisch onderzoek bemonsterd, teneinde de sedimentologische en paleo-landschappelijke evolutie van het gebied te bestuderen. Twee aspecten hebben er voor gezorgd dat deze gelegenheid een meerwaarde kon opleveren specifiek voor het onderzoek van de Holocene landschapsevolutie.

Vanuit een geomorfologisch gezichtspunt leverde het Deurganckdok voor het eerst een dwarsprofiel vanaf de huidige Scheldeloop op. Gelet op de grote breedte van de alluviale afzettingen in dit gebied is het niet mogelijk om vanaf het huidige oppervlak het begraven, fossiele landschap van het Laatglaciaal en het Holoceen, voor het begin van de veengroei $+/-6000 \mathrm{BP}$, te reconstrueren. Op basis van al het vorig onderzoek mag wel worden gesteld dat vanaf de actuele Pleistocene randen, het oppervlak van dit Pleistoceen vrij geleidelijk en zwak afhelt naar de actuele geul toe. Hieruit mag worden geconcludeerd dat de Scheldeloop voor 6000 BP zich ergens bevond in de zone van de huidige loop. De enorme verbreding bij de ontwikkeling van de getijdegeul heeft op haar 
beurt nog een belangrijk deel van het directe landschap rond de, naar schatting hoogstens $100 \mathrm{~m}$ brede, vroeg-Holocene Schelde vernietigd. Ontsluitingen zo dicht mogelijk bij deze oorspronkelijke loop zijn dan ook hoogst interessant, zowel voor het fysische als voor het archeologische landschap van die tijd. Van de ligging van het Deurganckdok mag gezegd worden dat zij optimaal aan deze voorwaarde voldoet.

Een tweede, belangrijk voordeel ditmaal was de permanente aanwezigheid van een onderzoeksteam van de Archeologische Dienst Waasland, waarin zich zowel archeologen als fysisch geografen - paleo-ecologen bevonden. Hierdoor zijn de graafwerken continu opgevolgd en zijn zonder meer belangrijke vondsten en vaststellingen gemaakt. De hierna volgende resultaten zijn afkomstig van wat als een type profiel van de veen- en alluviale afzettingen van de Benedenschelde mag gelden. Wegens de ligging diep in de alluviale vlakte gaat het om ongestoorde en volledige sedimentpakketten. Anderzijds is belangrijke, actieve menselijke aanwezigheid voor de grote strategische zogenaamde Farnèse-overstromingen tussen 1580 en 1640, aan het licht gebracht, waardoor het ook voor het eerst mogelijk werd om voor de duistere laatmiddeleeuwse periode gegevens te verwerven. Behalve het pollenonderzoek dat de gehele sequentie omvat, is ook zaden en vruchten en een preliminair diatomeeënonderzoek verricht in specifieke delen van het profiel.

\section{Situering en stratigrafie}

Figuur 1 geeft de ligging van het Deur-ganckdok in het Benedenschelde gebied en de plaats waar de sequentie van deze studie werd genomen.

Figuur 1. Situering van het Deurganckdok (2) in het Benedenscheldegebied.

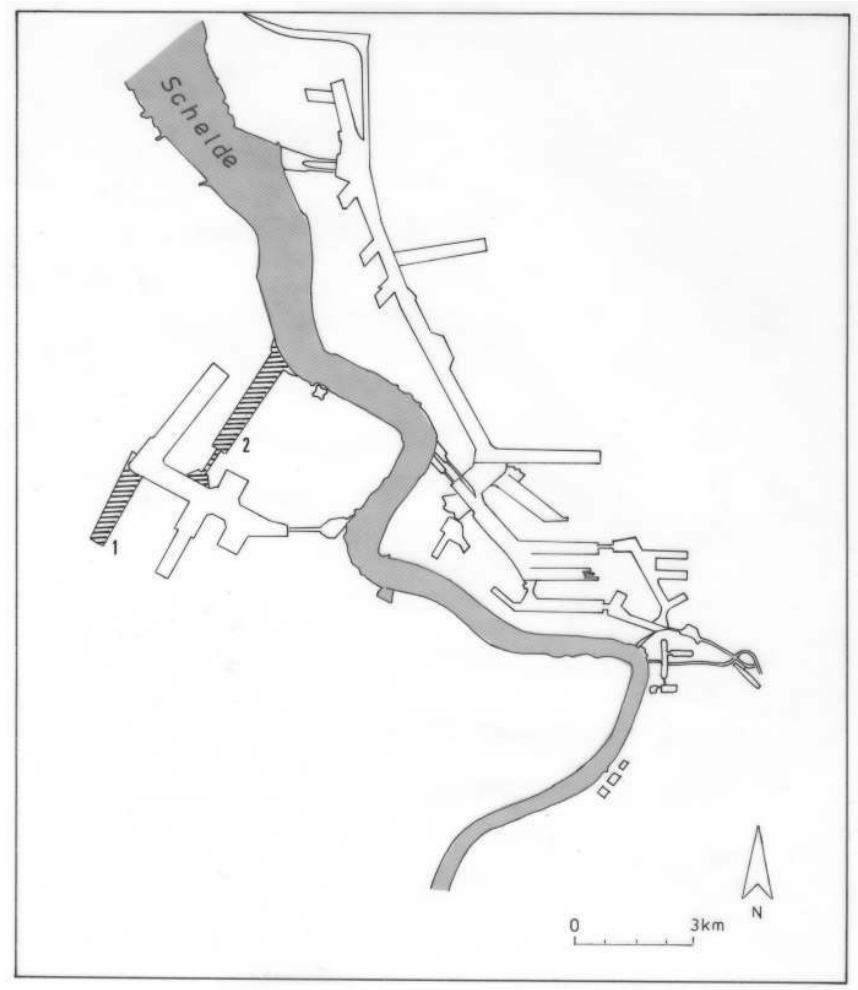


5 Figuur 2a geeft de algemene dwarsdoorsnede van de aanwezige sedimenten in het Deurganckdok weer; figuur $2 b$ beschrijft het onderzochte detailprofiel van de Holocene afzettingen, onderaan te beginnen vanaf de laat-Weichsel dekzanden. Op basis van vroeger onderzoek zijn hierin vijf genetische fasen onderscheiden, die niet op elke plaats in het profiel samen aanwezig zijn (Van Roeyen et al., 2001, pp. 445-451). Het hierna volgend onderzoek heeft evenwel 7 fasen onderscheiden, die samengevat als volgt kunnen worden omschreven :

Figuur 2a. Algemene dwarsdoorsnede van de sedimenten in het Deurganckdok.

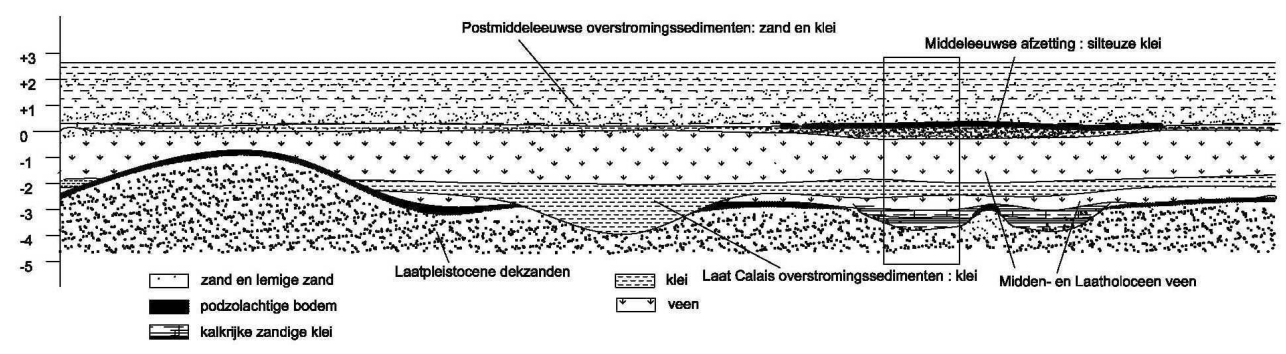

Figuur 2b. Detailprofiel van de onderzochte veensequentie.

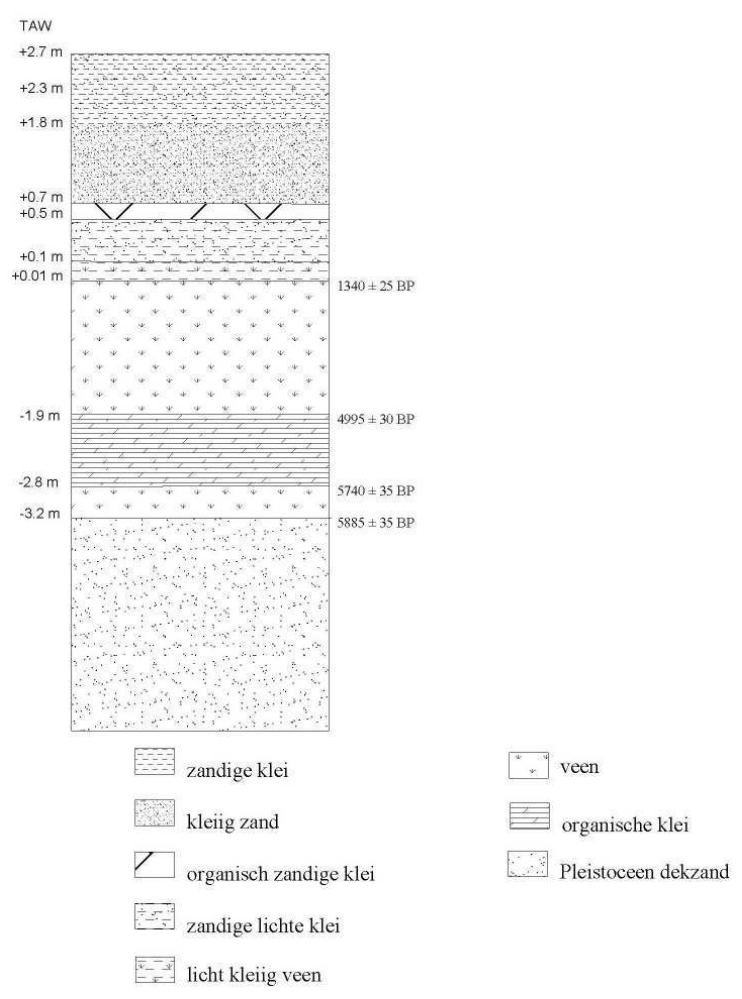

6 Laat-Weichsel dekzanden; deze vertonen een zwak golvend oppervlak met kleine ruggen en ondiepe depressies met sterk kalkrijke lichte kleien.

7 Kort na 6000 BP is ten gevolge van het snel stijgend zeepeil, het grondwaterniveau van de directe omgeving van de rivier in die mate gestegen dat zich laagveen begint te ontwikkelen. 
8 Slechts enkele eeuwen later, rond $5700 \mathrm{BP}$ wordt het veen traag overstroomd tengevolge van de toegenomen perimariene invloed. Enkel de hoogste ruggen van het dekzandlandschap, nog niet met veen overdekt, blijven gevrijwaard. De sedimentatie bestaat in hoofdzaak uit sterk organische klei.

Rond 5000 BP eindigt de overstroming snel en begint het veen opnieuw te groeien, ditmaal ook over de hoogst gelegen gedeelten. Deze veengroei gaat continu door tot in het midden van het eerste millenium van onze tijdrekening. Hierna volgt een periode van non-sedimentatie.

De top van het veen bevat klei en heeft een brokkelige structuur; dit werd pas duidelijk tijdens de preparatieprocedure van het paleobotanisch onderzoek (cf. aanwezigheid van kleipartikels).

11 Op sommige plaatsen zijn er op het veen lenzen van sterk fijn zandige klei afgezet. Op basis van archeologische vondsten kunnen deze sedimenten aan $13^{\mathrm{de}}-14^{\mathrm{de}}$ eeuwse overstromingen worden toegeschreven.

12 Aan de top van fase 6 bevindt zich een dunne laag organische zandige klei, die op basis van het archeologisch onderzoek als het loopvlak van fase 6 mag worden geïnterpreteerd. De strategische, catastrofale zgn Farnèse-overstromingen tussen 1580 en 1640 dienen nagenoeg volledig verantwoordelijk te worden gesteld voor de vorming van het actuele polderdek. Het is meer dan $2 \mathrm{~m}$ dik, sterk zandig over het grootste gedeelte. Enkel bovenaan kan het uit zware klei bestaan.

14 Het palynologisch onderzoek omvat het gedeelte van de sequentie van fase 2 t.e.m. fase 7 ; het zaden-en vruchtenonderzoek fase 3 t.e.m. 5 ; en het diatomeeënonderzoek de top van fase 4 t.e.m. 6 .

\section{${ }^{14}$ C-DATERINGEN}

15 Tabel 1 geeft een gedetailleerd overzicht van de radiometrische dateringen, uitgevoerd op de veenlagen (Van Strydonck, 2005).

\section{Pollen- en diatomeeënanalyse}

\section{Methode}

In totaal werden 45 monsters van de gehele sequentie voor pollenanalyse geselecteerd. Op grond van de beschikbare onderzoeksruimte en -tijd en de totale lengte van de sequentie werden de bemonsteringsafstanden vastgelegd op ca. 0,15 m. Bij stratigrafische overgangen werd een meer gedetailleerde bemonsteringsstrategie toegepast met intervallen van ca. $0,05 \mathrm{~m}$. Zowel de palynomorfen uit het veen als uit de kleiige sedimenten werden onderworpen aan de standaard-preparatiemethode van Faegri et al. (1989). De kleigradiënt werd door middel van gravitatiescheiding (sodiumpolytungstate) verwijderd. Indien de concentratie het toeliet, werden 500 tot 1000 palynomorfen per preparaat gedetermineerd en geteld. Voor de identificatie van het pollen en de sporen werd gebruikgemaakt van een aantal standaard-determinatiesleutels (Punt et al., 1976-1995 ; Faegri et al., 1989 ; Moore et al., 1991) en de referentiecollectie van het Vlaams Instituut voor het Onroerend Erfgoed (VIOE). Voor de non-pollen palynomorfen werd uitvoerig verwezen naar afbeeldingen en beschrijvingen van van Geel en anderen 
(Bakker, van Smeerdijk, 1980, pp. 95-163 ; Pals et al., 1980, pp.371-418; van Geel, 1976 ; van Geel et al., 1981, pp.367-448; van Geel et al., 1986, pp.31-61; van Geel, 2001, pp. 99-119; van Geel et al., 2003, pp. 797-940 ; van Geel en Aptroot, 2006). De kwantitatieve gegevens van elke getelde familie, genus en/of soort werden per geanalyseerd diepteniveau op basis van een pollendiagram procentueel uitgedrukt in verhouding tot de pollensom, d.i. de totale som van bomen en struiken (AP, arboreal pollen) en kruiden (NAP, non-arboreal pollen) ${ }^{1}$, waarna ze geëvalueerd en geïnterpreteerd werden.

Op basis van het pollenonderzoek en de macroscopische gegevens werden ook 13 monsters geselecteerd uit de overgang van venige naar kleiige sedimenten voor een preliminaire diatomeeënanalyse. Het organisch materiaal in de monsters werd verwijderd door een behandeling met $\mathrm{H}_{2} \mathrm{O}_{2}(30 \%)$ gedurende 72 uur. Vervolgens werden de monsters drie maal gespoeld met gedestilleerd water en tenslotte ingebed in naphrax . Voor de identificatie van de taxa werd gebruik gemaakt van Denys \& Verbruggen (1989), Sabbe (1997), Kyulenstierna (1989) en Krammer \& Lange-Bertalot (1997).

\section{Resultaten (fig. 3a en 3b ; fig. 4)}

In de onderzoeksresultaten worden de verschillende biostratigrafische zones op basis van de vertegenwoordigde preparaten per lithostratigrafische eenheid besproken (zie ook fig. 2).

Figuur 3a. Procentuele weergave (pollen) van het palynologisch onderzoek (met vergroting x5).

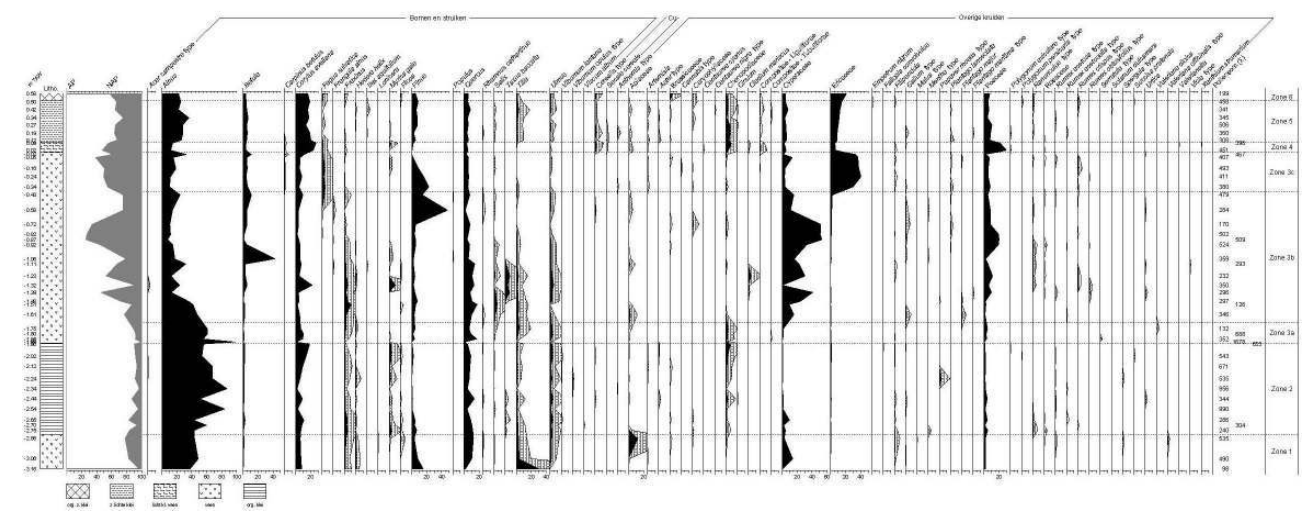




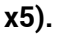

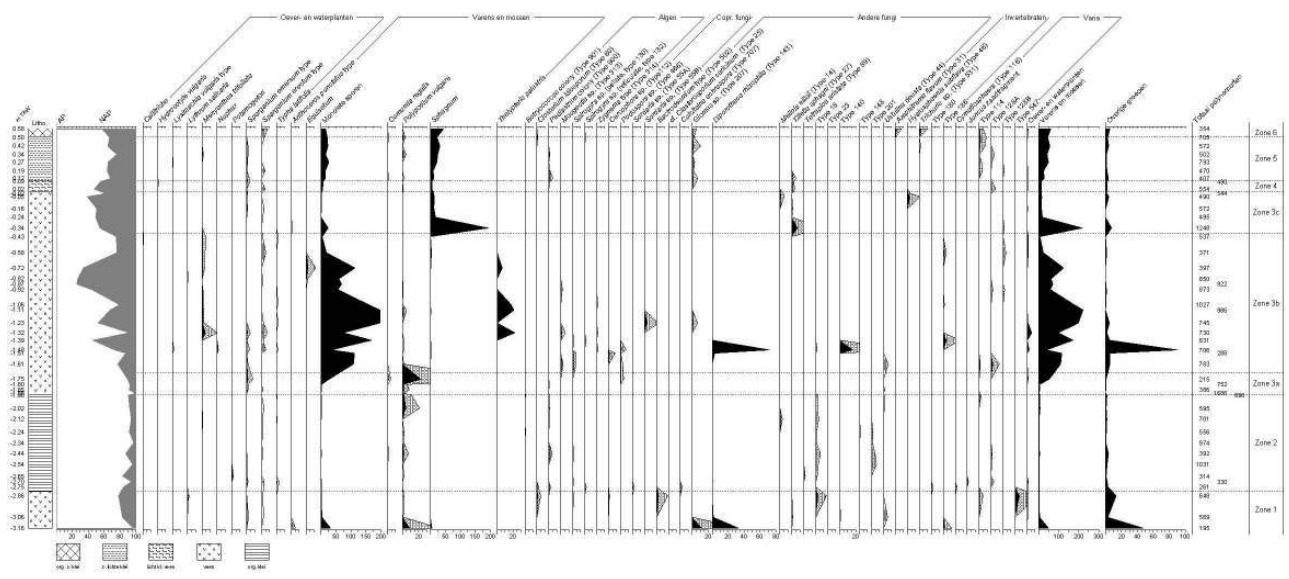

Figuur 4. Histogram van het diatomeeënonderzoek.

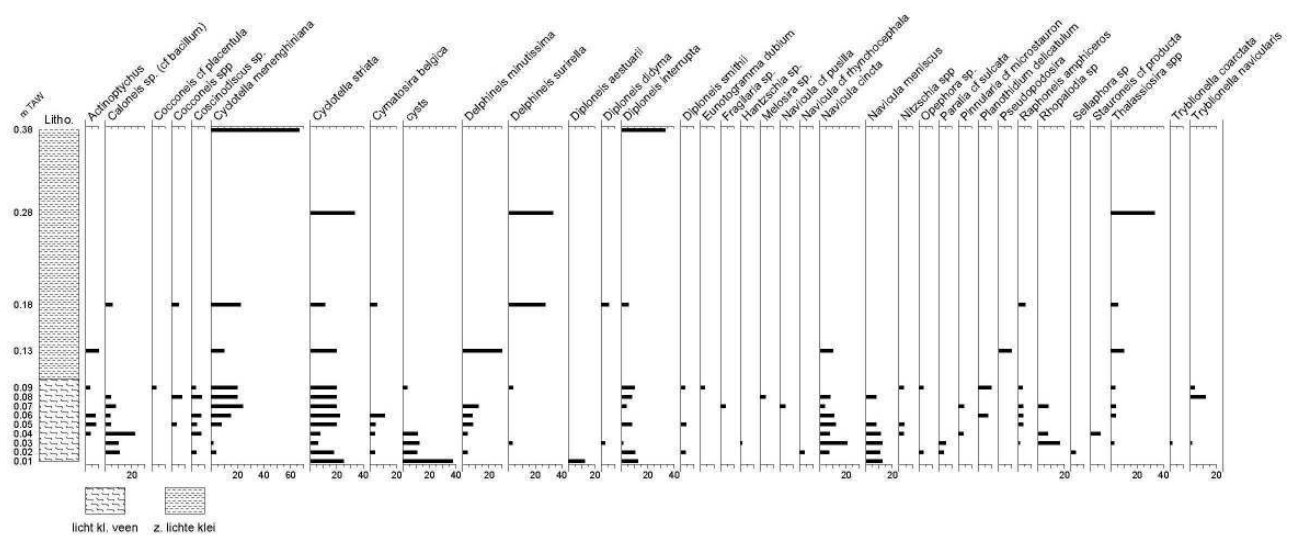

Zone 1 : -3,2 m TAW tot -2,8 m TAW : veen : Prep. 1 - 3

De AP/NAP-verhouding bedraagt ca. $80 / 20 \%$. Bij het boompollen (AP) is Alnus met ca. $45 \%$ dominant, gevolgd door Quercus (ca. $12 \%$ ) en Corylus avellana (ca. 7 \%). Tilia kent hoge waarden aan de basis van de sequentie, maar neemt sterk af naar de top toe (ca. $4 \%$ ). Dezelfde evolutie, maar minder uitgesproken, is waar te nemen in de pollenwaarden van Pinus. Andere bomen en struiken, zoals Betula, Fraxinus excelsior, Hedera helix, Lonicera, Salix en Ulmus, halen percentages tussen $0,5 \%$ en $2 \%$. Ook het pollen van het Rhamnus cathartica en Picea is sporadisch aanwezig. Bij de kruiden (NAP, ca. $20 \%$ ) vormen Cyperaceae en Poaceae de belangrijkste plantenfamilies. Andere kruidachtigen zijn, op uitzondering van Apiaceae in preparaat 3, zeldzaam. Oever- en waterplantenplanten, zoals Typha latifolia, Lythrum salicaria, Sparganium erectum type en Sparganium emersum type kennen een zeer beperkt aandeel. Aan de basis van de sequentie zijn monolete sporen, Polypodium vulgare en Sphagnum goed vertegenwoordigd. Bij de non-pollen 
palynomorfen bereiken ook Diporotheca rhizophila en het Glomus sp. hoge waarden. Ustulina deusta verschijnt in preparaat 2, terwijl het Bactrodesmium type, type 18 en type 547 typisch zijn voor preparaat 3.

\section{Zone 2 : -2,8 m TAW tot -1,9 m TAW : organische klei : Prep. 4 - 13} ), maar sterke fluctuaties verschijnen in de pollenwaarden van Alnus, Corylus avellana en Quercus; en in minder mate in deze van Tilia, Ulmus en Fraxinus excelsior. In vergelijking met de veenbasis neemt Alnus hier ontzettend toe, met pieken tot ca. $85 \%$. Quercus en Corylus avellana worden in zekere mate geattesteerd. Myrica gale is aanwezig en bereikt ca. $5 \%$. Taxus baccata, het Viburnum lantana en Viburnum opulus type zijn schaars vertegenwoordigd. De kruiden (NAP), met hoofdzakelijk Poaceae, Cyperaceae en Chenopodiaceae, bekleden slechts een pollenaandeel van ca. $10 \%$. Cyperaceae nemen gradueel af tot $2 \%$, terwijl Chenopodiaceae percentages tot $7 \%$ bereiken naar het einde van de zone toe. Ericaceae ind. vormen minder dan $2 \%$ van het kruidenaandeel. De waarden van de waterplanten, sporen van varens en mossen zijn laag. Als non-pollen palynomorfen zijn type 18 en type 201 regelmatig aanwezig, hetzij in zeer geringe aantallen.

\section{Zone 3 : -1,9 m TAW tot 0,01 m TAW : veen : Prep. 14 - 36}

Zone 3a: Preparaten 14-17 Het AP/NAP verhoudt zich procentueel tot ca. 90/10\%. Bij het boompollen kent Alnus een piek (98\%) in preparaat 14, maar stagneert dan tot $60 \%$ in de volgende preparaten. Quercus en Corylus avellana zijn goed vertegenwoordigd. Pinus, Tilia en Ulmus bereiken percentages tot $5 \%$. Betula en Fraxinus hebben echter zeer lage pollenwaarden. Poaceae en Chenopodiaceae zijn de belangrijkste vertegenwoordigde families bij de kruiden. Ericaceae en de andere kruidachtigen zijn praktisch afwezig. Bij de waterplanten worden enkel Sparganium erectum type en Sparganium emersum type waargenomen.

Zone 3b: Preparaten 18-31 De AP/NAP-verhouding kent hier een grilliger verloop (85-30/15-70 \%). Bij de bomen en struiken is het aandeel van Alnus nog steeds belangrijk, maar daalt sterk tot ca. $20 \%$. Betula, Fraxinus excelsior, Quercus en Salix nemen echter matig toe. Betula kent weliswaar een piek van ca. $40 \%$ in preparaat 25 , terwijl Pinus in preparaat 30 ca. $45 \%$ bereikt. Tilia neemt gestaag af. Myrica gale is hoofdzakelijk in preparaat 22 geconcentreerd en Taxus baccata van preparaat 21 tot en met 23. Fagus sylvatica komt op naar het einde van de zone toe (tot ca. $4 \%$ ). Het Cerealia type verschijnt voor de eerste maal in de sequentie. Bij de andere kruiden is er een uitgesproken, deels fluctuerende stijging in het pollenaandeel van de Cyperaceae. Deze blijven dominant doorheen de gehele zone (tot ca. 50 \%). Onder de Cyperaceae kan Cladium mariscus tot op soortniveau onderscheiden worden. Ook Poaceae en andere planten, waaronder Plantago lanceolata, Galium type, Rumex acetosa type en Mentha type zijn in meerdere mate aanwezig. Bij de waterplanten valt hoofdzakelijk Menyanthes trifoliata, Sparganium emersum type, Sparganium erectum type en Typha latifolia te bespeuren. Zeer hoge waarden van monolete sporen en Thelypteris palustris worden bij de varens geattesteerd. Van de non-pollen palynomorfen zijn naast sporen van algae (o.a. Spirogyra sp., Zygnema type en Mougeotia sp. en mogelijk Type 128A en B) ook enkele sporen van coprofiele fungi (o.a. Cercophora sp., Type 55B, Podospora sp.) aanwezig. Diporotheca rhizophila kent een piek in preparaat 20.

Belgeo, 3 | 2006 
2 3 : Preparaten 32-36 Het boompollen daalt van ca. $80 \%$ naar ca. $50 \%$. Alnus blijft percentages tot $20 \%$ à $30 \%$ behouden. De piek van Pinus (cf. vorige zone) neemt hier sterk af en verdwijnt naar het einde van de zone toe. Fagus sylvatica blijft onmiskenbaar aanwezig en neemt in beperkte mate toe. Carpinus betulus en Myrica gale verschijnen. De pollencurven van Fraxinus excelsior en Ulmus nemen geleidelijk af, terwijl Tilia volledig verdwijnt. Quercus en Corylus avellana houden stand met percentages tot $10 \%$. Bij de kruiden ruimt de dominantie van Cyperaceae plaats voor Ericaceae. Poaceae blijven in zekere mate vertegenwoordigd (ca. $10 \%$ ). Ook kruiden, zoals Plantago lanceolata, enkele Rumex types en Filipendula, worden opnieuw in wisselende waarden waargenomen. Als waterplanten worden Sparganium erectum type en Sparganium emersum type geattesteerd. Bij de mossen kent Sphagnum een aanzienlijk percentage aan het begin van de zone (tot ca. $200 \%$ ) en stagneert vervolgens op ca. $20 \%$. Monolete sporen zijn weliswaar in zeer beperkte mate aanwezig. Tilletia sphagni kent aan het begin van de zone een zeker aandeel bij de non-pollen palynomorfen, terwijl Hyalosphaenia subflava en Meliola ellisii naar het einde toe verschijnen.

\section{Zone 4 : 0,01 m TAW tot 0,1 m TAW : licht kleiig veen : Prep. 37 - 38}

De verhouding AP/NAP kent een zekere status quo (50/50 \%) t.o.v. de vorige zone. Corylus avellana breidt uit tot ca. $20 \%$ en is nu het best vertegenwoordigd bij de bomen en struiken. Alnus heeft nog slechts een pollenwaarde van ca. $10 \%$. Tilia is afwezig, Fagus sylvatica daalt gestaag. De overige aanwezige boomsoorten (o.a. Fraxinus excelsior, Pinus, Quercus en Ulmus) zijn beperkt in aantal. Onder de cultuurgewassen verschijnt het Cerealia type samen met Secale cereale. Bij de andere kruiden is er een stijging in de pollenwaarden van Chenopodiaceae en Poaceae waar te nemen. Ericaceae en Cyperaceae zijn matig vertegenwoordigd. Waterplanten (o.a. Sparganium erectum type en Sparganium emersum type) en varens en mossen (o.a. Sphagnum) zijn beperkt in aantal. Bij de non-pollen palynomorfen valt type 128A, het Glomus sp. en Tilletia sphagni op te merken.

venpaketten onder $0,01 \mathrm{~m}$ bevatten geen gefossileerde diatomeeënschaaltjes. In het licht kleiig veen tussen 0,01 en $0,1 \mathrm{~m}$ worden slecht bewaarde en vaak gebroken schaaltjes gevonden van taxa met een sterk uiteenlopende ecologie. Zo komen zoet- tot brakwater taxa (b.v., Caloneis cf. bacillum, Planothidium delicatulum) samen voor met aërofiele soorten (b.v. Hantzschia sp.), estuariene soorten (Cyclotella striata, Thalassiosira spp.) en zelfs mariene/estuariene diatomeeën (Actinoptychus).

\section{Zone 5 : 0,1 m TAW tot 0,5 m TAW : zandige lichte klei : Prep. 39 - 44}

In deze zone evolueert het aandeel van de AP t.o.v. de NAP tot een verhouding van ca. $70 / 30 \%$. Onder de bomen en struiken is Alnus dominant. Pinus en Ulmus stijgen gestaag, Tilia verschijnt opnieuw. Ook hier is het Cerealia type en Secale cereale als cultuurgewassen aanwezig. Bij de andere kruiden nemen de Poaceae af. Samen met de Ericacea, Cyperaceae en Chenopodiaceae vormen ze het hoofdbestanddeel van de kruidenvegetatie. Als waterplanten treffen we hoofdzakelijk Sparganium erectum type en Sparganium emersum type aan. De varens en mossen worden voornamelijk vertegenwoordigd door monolete sporen en Sphagnum. Bij de non-pollen palynomorfen is het Glomus sp., samen met type 114, constant aanwezig. Trichuris sp. komt op naar het einde toe.

De schaaltjes van de diatomeeën tussen 0,1 en 0,38 m zijn in de meeste gevallen gebroken en slechts in heel lage concentraties aanwezig in de sedimenten. Typische estuariene 
soorten domineren in deze zone met voornamelijk taxa die voorkomen op slikken en getijdenplaten (Diploneis interrupta, Delphineis surirella; Kuylenstierna 1990). De typische zoet- en brakwater taxa die gevonden werden in de voorgaande zone, zijn hier grotendeels afwezig.

\section{Zone $6:$ 0,5 m TAW tot 0,7 m TAW : organische zandige klei : Prep. 45} pollendata uit de vorige zone. Op uitzondering van een beperkte toename in een aantal kruidentypes, zoals Brassicaceae en Ericaceae, en de varens en mossen zijn er geen opmerkelijke verschillen met de vorige zone.

\section{Interpretatie en discussie}

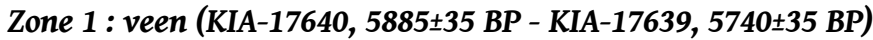
een dicht gemengd bos aanwezig, met als belangrijkste boomsoorten Quercus, Tilia, Ulmus, Pinus en Fraxinus excelsior. In de sterk organische basis van de sequentie (cf. preparaat 1) duiden de hoge waarden van Tilia, Pinus, varens en mossen hoofdzakelijk op een beperkte bewaring van het overige pollen ( $\mathrm{cf}$. de zeer lage pollensom). Deze 'oververtegenwoordigde' taxa zijn uiterst resistent aan afbraak in de bodem en daarenboven gemakkelijk te identificeren (Janssen, 1974, pp.18-20 ; Havinga, 1984, pp. 541-558; Waller, 1994, p. 25). In tegenstelling tot windbloeiers (o.a. Alnus en Quercus) zijn Tilia en andere insektenbloeiers, zoals Filipendula en Typha latifolia, over het algemeen in de pollendata ondervertegenwoordigd (Janssen, 1974, p. 21). Hun verspreidingscapaciteit neemt enorm af naarmate de afstand tot de verspreidingsbron groter wordt (Janssen, 1974, p. 78; Waller, 1994, p. 95). Corylus avellana vinden we mogelijk aan de randen van het gemengd bos terug. Het pollen van Picea dient als allochtoon te worden beschouwd. Het kan toegeschreven worden aan atmosferische lange afstandstransport of aan remaniatie door alluviaal transport.

Ondanks de vertegenwoordiging van enkele lichtminnende planten, zoals Ericaceae en Poaceae, zijn er nauwelijks of geen sporen van bosontginning aanwezig. Bewijzen voor akkerbouw en/of veeteelt komen in de pollendata niet tot uiting. Aan de hand van archeologische vondsten wordt op de hoger gelegen Pleistocene gronden wel enige vorm van menselijke activiteit geattesteerd (Crombé, Perdaen \& Sergant, 2005, pp. 141-179). De 
palynologische visibiliteit van deze activiteiten wordt mogelijk door de pollen-influx van lokale windbloeiers op het veen (o.a. Alnus) gemaskeerd.

De landschapsreconstructie van deze zone beantwoordt sterk aan de vegetatiekenmerken van het Atlanticum, waarin Quercus, Alnus, Corylus avellana, Tilia en Ulmus als de belangrijkste boomsoorten worden aanzien (Janssen, 1974, pp. 55-57 ; Verbruggen et al., 1996, pp. 565/573; Verbruggen 1999, 108). Vergelijkbare palynologische resultaten uit deze periode werden ook op andere bemonsterde plaatsen in Doel zelf (Minnaert \& Verbruggen, 1986, p. 203) en in de omgeving (bv. Melsele en Oorderen) geregistreerd (Van Roeyen et al., 1991, pp. 45-46 ; Munaut, 1967a, p. 39).

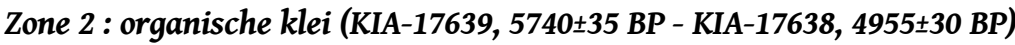

In tegenstelling tot pollenassemblages van gestratifieerde veensecties, zijn deze van (peri)mariene en alluviale afzettingen moeilijk te interpreteren. Ten gevolge van mobilisatie en lange afstandstransport in water zijn het pollen en de sporen van kleitransities, naast de lokale atmosferische influx, afkomstig van verschillende bronnen. Dit maakt een lokale en zelfs regionale landschapsreconstructie van dergelijke pollenassemblages moeilijk. Uit de organische klei zien we bijvoorbeeld in de pollencurve van Alnus zeer uitgesproken fluctuaties optreden. Myrica gale is zelfs mogelijk allochtoon, gezien het niet kan gedijen in een gemengd bos op zandgronden; het wordt meestal aangetroffen op oligotroof hoogveen (Barkman, 1992, p.175; Waller, 1994, p. 100 ; Verbruggen et al., 1996, p. 572 ; Lambinon et al., 1998, p. 104). Daarentegen vormt het vaak ook een bestanddeel van laagveen (Weeda et al,. 1985). Weliswaar gaat het in deze afzetting echter om in water en in suspensie getransporteerde pollen, waarvan de herkomst moeilijk te bepalen is.

Anderzijds kan met het paleo-ecologisch onderzoek van dergelijke sedimenten nuttige informatie verkregen worden over de paleohydrologie van een gebied. De vroege getijdenwerking in het Beneden Scheldebekken gedurende het Laat-Atlanticum werd al door Verbruggen en anderen aangetoond (Minnaert \& Verbruggen, 1986, pp. 203-204; Van Roeyen et al., 1991, p. 45 ; Verbruggen \& Denys, 1995). Bewijzen voor clastische, brakke afzettingen werden op basis van pollen- en diatomeeëndata in kleiige sedimenten te Doel en Melsele gevonden. Vooral hoge waarden ( $5 \%$ en meer) van Chenopodiaceae en de aanwezigheid van Armeria doen de invloed van brak water vermoeden. Gelijkaardige waarden van Chenopodiaceae werden ook in dit kleisediment gevonden. Hoewel Chenopodiaceae ook als aanwijzing voor menselijke activiteit (voornamelijk als ruderales, cf. Behre, 1986) kunnen geïnterpreteerd worden, wordt toch een voorkeur aan de eerste hypothese gegeven. Gezien de afwezigheid van andere duidelijke antropogene indicatoren binnen deze zone, is de (beperkte) invloed van getijdenwerking immers niet uit te sluiten.

Uit het zaden- en vruchtenonderzoek van archeologische contexten in de omgeving van deze sequentie werd ook een hypothese voor de aanwezigheid van een hardhoutooibos geformuleerd (Bastiaens et al., 2005, pp. 277-278/295). De datering van dit hardhoutooibos valt grotendeels samen met de beginfase van de organische klei-afzetting. Op grond van de palynologische gegevens van dit sediment komt de zichbaarheid van het hardhoutooibos echter niet tot uiting. 


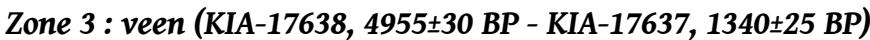

Zone 3a: preparaten 14-17 Aan het begin van deze veensectie is het eutrofe elzenbroekveen tijdelijk hersteld. Ondanks een lichte stijging in de pollenwaarden van Corylus avellana, Quercus en Poaceae zijn de vegetatiekenmerken sterk vergelijkbaar met deze van het onderste veenpakket. Een elzenbroekbos domineert het lokale milieu. Op de drogere zandgronden wordt een gemengd bos aangetroffen. Menselijke indicatoren worden nog steeds niet gedetecteerd. Naar het einde van deze eerste zone toe duiden de stijgende waarden van monolete sporen, en ook Polypodium vulgare in het bijzonder, niet zo zeer op een beperkte bewaring van de overige pollen en sporen (zoals reeds eerder opgemerkt werd), maar kondigen ze het begin van mesotrofe veengroei aan.

Deze zone wordt op grond van de absolute datering van de veenbasis (cf. 4995 $\pm 30 \mathrm{BP}$ ) volgens de chrono- en pollenzonatie van Zagwijn \& van Staalduinen (1975) tot het Subboreaal (vanaf ca. 5000 BP) gerekend, terwijl de vegetatie hier eerder nog een Atlantisch karakter vertoont. De meer langdurige, regionale biozonatie voor het Atlanticum in Vlaanderen (ca. 7500 BP- 4000 BP), opgesteld door Verbruggen (1999, p. 573), geniet hier dan ook de voorkeur.

38 Zone 3b: preparaten 18-31 De mesotrofe, nutriëntarmere fase in de veengroei wordt hoofdzakelijk gekenmerkt door zeggeveen. De gesloten vegetatie, bestaande uit elzenbroeken, ruimt plaats voor een open vegetatie, waarin Cyperaceae (met Carex en Cladium mariscus) en varens (o.a. monolete sporen, waarvan ook Thelypteris palustris) lokaal sterk uitbreiden. Samen met een eerste, korte stijging van Betula en in een laatste fase Pinus duiden ze op een meer open bosvegetatie en een toenemende verdroging. Ze kondigen over het algemeen de overgang naar een oligotrofiëring aan (Verbruggen, 1986, p. 204 ; Casparie \& Streefkerk, 1992, p. 113 ; Waller, 1994, p. 91).

9 In de eerste helft van de mesotrofe zone vindt, zoals bij de veensecties van Terneuzen, Zandvliet en Oorderen (Munaut 1967a), een lichte stijging van Fraxinus plaats en verschijnt Taxus baccata opnieuw. Dit fenomeen wordt volgens Munaut (1967a, p. 13) algemeen aan de eerste helft van het Subboreaal (ca. 4300 BP-3800/3500 BP) toegeschreven. Of dit ook voor dit gedeelte van de zone opgaat, valt moeilijk uit te maken. Op basis van de pollendata vermoeden we dat de Laat-Atlantische vegetatiekenmerken zich hier nog even doorzetten.

Quercus lijkt toe te nemen, wat op de drogere milieu-omstandigheden kan wijzen. Anderzijds doet het uitblijven van een duidelijke toename in de pollenwaarden van Corylus avellana, gecombineerd met een lichte stijging van Salix, echter vermoeden dat het hier enkel gaat om een betere pollenverspreiding van Quercus in het mesotroof, meer open milieu (dit in tegenstelling tot de dichte elzenbroeken). Zo ook wordt de zichtbaarheid van de kruiden (hoofdzakelijk natte graslandplanten) bevorderd. De waterplanten en aanwezige algae (cf. supra) geven het lokale, vochtige milieu van ondiepe plassen weer (van Geel, 2001, p. 101). Menselijke invloed op het landschap wordt niet of nauwelijks waargenomen. De aanwezige coprofiele fungi kunnen zowel op begrazing door vee, als het vergaan van hout duiden (cf. ook Ustulina deusta) (van Geel, 2001, p. 106).

De tweede helft van de zone beantwoordt sterker aan de Subboreale vegetatiekenmerken (Munaut, 1967a ; Minnaert \& Verbruggen, 1986, p. 204 ; Verbruggen, 1999, p. 565). Het zeggeveen is lokaal nog steeds aanwezig. Op de drogere zandgronden komt Fagus sylvatica 
nu op, terwijl Fraxinus excelsior, Ulmus en Tilia geleidelijk afnemen. Quercus en Corylus avellana blijven echter continu vertegenwoordigd.

Daarnaast worden de eerste sporen van menselijke activiteit waargenomen. De dalende Ulmus-waarden weerspiegelen een landnam. Naar analogie met andere palynologische gegevens uit Laag- en Midden-België wordt ze weliswaar later in de tijd gesitueerd (ca. 4000-3500 BP) dan in andere Noordwest-Europese regio's (Munaut, 1967a ; Munaut, 1967b, p. 18 ; Minnaert \& Verbruggen, 1986, p. 204). Eén enkele uitzondering vormt echter het paleo-ecologisch onderzoek van een profiel te Wortel in het Mark-dal (Noorderkempen), waarbij de menselijke invloed reeds tot uiting komt aan het begin van het Subboreaal (De Ploey, 1961, pp. 82-86/100 ; Beyens, 1984, pp.89-95). Samen met deze Ulmus-daling verschijnen eveneens andere antropogene indicatoren, zoals Plantago lanceolata en in een latere fase ook het pollen van het Cerealia-type. In een dergelijk vochtig milieu vormt veeteelt waarschijnlijk de belangrijkste economische activiteit, terwijl op de hoger, gelegen droge zandgronden graanteelt zich meer zal manifesteren.

In de eindfase van de mesotrofe veengroei neemt Pinus nog enorm toe. Vermoedelijk gaat het hier om een lokale vestiging van een dennenbos. Door edafische veranderingen (drogere fase) kunnen ze namelijk een sterke tijdelijke uitbreiding kennen (mogelijk één of enkele generaties van dennen) (Waller, 1994, p. 91, naar Godwin, 1968).

Zone 3c: preparaten 32-36 De oligotrofiëring vangt aan met een korte expansie van Sphagnum en Tilletia sphagni. De rest van de zone wordt hoofdzakelijk gedomineerd door Sphagnum-heideveen. Naar het einde toe vindt ook een kleine uitbreiding van Myrica gale plaats, dat vermoedelijk een stilstand in de veengroei geeft (Verbruggen \& Semey, 1993, p. 63). Deze verstoring wordt ook bevestigd door de aanwezigheid van Hyalosphaenia subflava (van Geel, 1976). Menselijke activiteit komt in beperkte mate tot uiting in deze oligotrofe fase.

Gelet op het verschijnen van Carpinus betulus en de toenemende percentages van Fagus sylvatica kan deze zone in het Subatlanticum (2800 BP- nu) gesitueerd worden (Janssen, 1974, p. 57; Munaut, 1967a, p.14; Janssens \& Ferguson, 1985, p.93; Minnaert \& Verbruggen, 1986, p. 205 ; van Beurden, 1999, p. 279).

Op het vlak van de hoogveenontwikkeling vertoont deze fase in zekere mate parallellen met de bevindingen die in Nederland en in de rest van Europa worden vooropgesteld (van Geel, Buurman \& Waterbolk, 1996 ; van Geel, Raspopov, van der Plicht \& Renssen, 1998 ; van Geel \& Renssen, 1998). In dit geval wordt voor deze veensequentie een relatieve aanwijzing gegeven voor een hoogveenontwikkeling vanaf het begin van het Subatlanticum (zie opkomst van Carpinus betulus), mogelijk gerelateerd aan een toenemende vernatting ten gevolge van klimatologische veranderingen. Gezien het veenonderzoek in Vlaanderen vooralsnog te beperkt is, lijkt het ons iets echter te voorbarig hierover reeds een definitieve uitspraak te doen. Slechts aanvullend onderzoek van andere veensequenties kan in de toekomst over dergelijke problematiek een uitsluitsel bieden.

Daarnaast wordt met deze zone ook aangetoond dat de veengroei zich verderzet tot in de vroege Middeleeuwen. Sporen van veenontginning werden echter niet aangetroffen, waardoor de veensequentie als dusdanig als vrij intact kan beschouwd worden. 


\section{Zone 4 : licht kleiig veen (KIA-17637, 1340 25 BP - ...)}

BP, cal. ca. 7 de eeuw n.C) bij de top van het veen als een terminus antequem. De $14^{-}-15^{\mathrm{d}}$ eeuwse archeologische vondsten, aanwezig in deze organische zandige kleilaag, kunnen als een terminus postquem worden beschouwd (Van Roeyen et al., 2001, p. 450). Mogelijk moet dit sedimentpakket dan ook ten tijde van de eerste, historisch bekende overstromingen in de $14^{\text {de }}$ eeuw gedateerd worden (Gottschalk, M.K.E., 1971, pp. 357-359 ; Van Roeyen et al., 2001, p. 450). Dit heeft echter tot gevolg dat er een tijdshiaat van ca. 500-700 jaar aan voorafgaat, waarin relatief weinig sedimentatie plaatsvindt. Parallelle bevindingen van een energie-arm afzettingsmilieu in het betreffende gebied en de 
periode werden ook reeds vastgesteld door Denys \& Verbruggen (1989), alsook in de kustvlakte door Baeteman et al. (2002), dan wel vroeger in de tijd gesitueerd (ca. $2000 \mathrm{cal}$. yr BP- 1200 cal. yr BP). Vermoedelijk fungeerde dit gedeelte van het Wase Scheldepoldergebied als kombergingsgebied (Van Roeyen et al., 2001, p. 450).

\section{Zaden-en vruchtenonderzoek}

Om practische redenen (door de onveilige toestand van de wanden en de tijdsdruk bij de graafwerken) werd de bemonstering van dit onderzoek op een andere plaats in de nabijheid uitgevoerd (ca. $50 \mathrm{~m}$ van het palynologische profiel). Het onderzochte gedeelte omvat de fasen 3 t.e.m. 5, meer bepaald de organische klei en het bovenliggende veenpakket.

\section{Methode}

In totaal werden 9 monsters onderzocht, waarvan acht uit het veenpakket en één uit de organische klei. Elk monster had een gewicht tussen de 150 en de 160 g. In het laboratorium werden de monsters gedurende drie dagen geweekt in een $5 \% \mathrm{KOH}$ oplossing, en vervolgens gezeefd met drie zeven met een respectievelijke maaswijdte van 1, 0.5 en $0.25 \mathrm{~mm}$. Het residu werd nat opgeslagen en bekeken onder een olympus stereomicroscoop met opvallend en doorvallend licht (vergroting tussen 3.5 en 144x). De resultaten van het onderzoek werden uitgezet in een diagram, waarbij gebruik gemaakt werd van de absolute aantallen. In monster $\mathrm{nr} .8(20-25 \mathrm{~cm})$ werden blaadjes van Sphagnum sp. opgemerkt. Daar ze te talrijk waren om afzonderlijk te registreren werd de aanwezigheid ervan in het diagram weergegeven door een '+'-teken. De zaadjes die werden gedetermineerd als Carex sp. konden niet tot op soort worden gebracht. Er waren wel duidelijk twee verschillende types aanwezig, die in het diagram afzonderlijk werden weergegeven. De zaadjes die werden genoteerd als Carex sp. type 1 zijn biconvex en de zaadjes die werden genoteerd als Carex sp. type 2 zijn triconvex.

\section{Resultaten (fig. 5)}



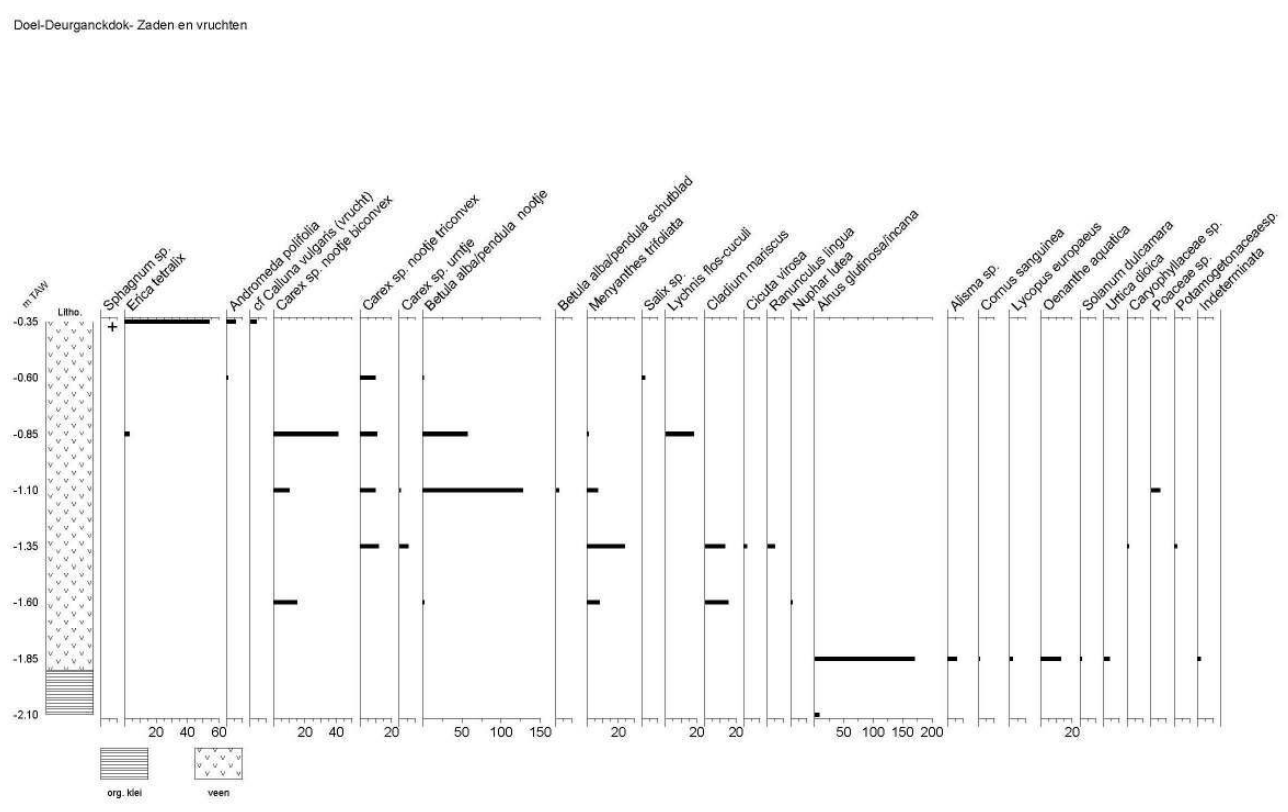

\section{$-2,8 m$ TAW tot $-1,9 m$ TAW : organische klei}

De onderzoeksresultaten van dit monster zijn zeer beperkt; de enige soort die wordt waargenomen, is Alnus glutinosa.

$-1,9 m$ TAW tot 0,01 m TAW : veen

In het onderste monster van dit pakket (nr. 2) worden opnieuw nootjes van Alnus glutinosa gevonden, maar ditmaal zijn ze veel prominenter aanwezig. Hoger in het geanalyseerde veenpakket zijn er geen nootjes van els meer gevonden. Onderaan het veenpakket komen nog een aantal andere soorten voor, die eveneens ontbreken in de bovenliggende niveau's: Alisma sp., Cornus sanguinea, Lycopus europaeus, Oenanthe aquatica, Solanum dulcamara en Urtica dioica.

Monster nr. 3 verschilt qua samenstelling totaal van monster nr. 2. Een Carex-soort van het type 1, Betula alba/pendula, Menyanthes trifoliata, Cladium mariscus en Nuphar lutea duiken in het vegetatiebeeld op.

In monster nr. 4 vinden we Cladium mariscus en Menyanthes trifoliata, maar de laatstgenoemde soort is op dit niveau duidelijker aanwezig. Naast deze twee soorten komen ook nog (een) Carex-soort(en) van het 2de type, Cicuta virosa, Ranunculus lingua en Poaceae sp. naar voor.

63 In nr. 5 en 6 komen de Carex-soort(en) van het eerste type en Betula alba/pendula tot uiting. Daarnaast blijven de zeggesoort(en) van het tweede type en Menyanthes trifoliata aanwezig. Erica tetralix wordt een eerste maal waargenomen; Lychnis flos-cuculi wordt weliswaar enkel op niveau 6 geattesteerd.

64 In monster nr. 7 worden voor het eerst Andromeda polifolia en Salix sp. opgemerkt. Betula alba/pendula manifesteren zich minder duidelijk dan de onderliggende niveau's, terwijl de zegge-soort(en) van het tweede type even belangrijk blijft (-ven).

In monster nr. 8 worden Erica tetralix, Calluna vulgaris en Sphagnum sp. de belangrijkste (zichtbare) componenten van de vegetatie. Ook Andromeda polifolia wordt belangrijker tov het onderliggende veen. Alle andere reeds genoemde soorten verdwijnen uit beeld. 

in het poldergebied stroomafwaarts Antwerpen. De datering van de top is nagenoeg de jongste die tot nu toe voor de top van het veen werd gemaakt ; deze van de basis benadert eveneens dicht de oudste datering van het begin van de veengroei (Munaut, 1967a en b, Van Roeyen et al., 2001, p. 449). transgressie zo diep in de Benedenschelde vallei. Ook de tijdsduur en het verloop ervan werden duidelijker aangetoond dan in het profiel van Doel dat in 1986 werd onderzocht door Minnaert en Verbruggen, waarschijnlijk omdat het Deurganckdok dichter bij de toenmalige Schelde is gelegen. De duurtijd van 700 jaar geeft aan dat het hier niet om een 
eenmalige overstroming gaat, maar wel degelijk over een belangrijke uitbreiding van de mariene invloed, tevens de meest landinwaartse van het Holoceen.

Tussen het einde van deze transgressie (ca. 5000 BP) en het einde van de veengroei kunnen we in de sequentie alle botanische fasen van de tweede helft van het Holoceen, zoals die voor Noord-België bekend zijn, terugvinden. Hier wordt opnieuw aangetoond dat dit laatste deel van de Benedenschelde vallei als een perimarien systeem fungeerde waarin zich hoogveenomstandigheden konden ontwikkelen. Potentieel is alles hier aanwezig om uit een groter oplossend vermogen gedetailleerde gegevens te verwerven over de paleo-ecologische en klimatologische evolutie van het Subboreaal en Subatlanticum.

Een tweede opvallend resultaat komt uit de topzone van het profiel. De drie paleobotanische disciplines uit deze studie leidden ieder op hun manier tot een zeer eenduidige conclusie. Zoals reeds vermeld, werd het bestaan van fase 5, waarvan het sediment uit licht kleiig veen bestaat, slechts ontdekt op basis van het pollen- en diatomeeënonderzoek. Beide disciplines ondersteunen de idee dat het einde van de veengroei in relatief rustige overstromingsomstandigheden heeft plaats gegrepen. Aangezien de ${ }^{14} \mathrm{C}$-datering aan de top van de fase 4 , het bovenste veen, is genomen, betekent dit dat het licht kleiig veen nadien is afgezet. Het verschijnen van Secale cereale in deze laag zou eerder naar de $10^{\text {de }}$ en $11^{\text {de }}$ eeuw verwijzen dan vroeger. Alsdusdanig bevestigt dit de vooropstelling van Denys en Verbruggen (1989) dat er een periode van non-depositie van meerdere eeuwen mag worden ingelast tussen het natuurlijk beëindigen van de veengroei in de $6^{\text {de }}-7^{\text {de }}$ eeuw en de middeleeuwse overstromingen.

De daarop volgende overdekking met een pakket van zandige lichte klei, in de $13^{\text {de }}$ of $14^{\text {de }}$ eeuw weerspiegelt een totaal gewijzigde situatie. De archeologische vondsten op deze laag zijn dermate belangrijk dat ze toelaten te besluiten tot een relatering met de eerste echte getijden overstromingen en tevens met het nadien tijdelijk in gebruik nemen van deze zones boven het veen.

BIBLIOGRAPHIE

BAETEMAN C., SCOTT D.B. \& VAN STRYDONCK M. (2002), « Changes in coastal zone process at a high sea-level stand: a late Holocene example from Belgium », Journal of Quaternary Science 17 (5-6), pp. 547-559, Chichester, John Wiley and sons, Ltd.

BAKKER M. \& VAN SMEERDIJK D.G. (1980), « A Palaeoecological study of a Late Holocene section from "Het Ilperveld", Western Netherlands ", Review of Palaeobotany and Palynology 36, pp. 95-163, Amsterdam, Elsevier.

BARKMAN J.J. (1992), «Plant communities and synecology of bogs and heath pools in the Netherlands ", in VERHOEVEN J.T.A. (ed), Fens and Bogs in the Netherlands: Vegetation, History, Nutrient Dynamics and Conservation (Geobotany 18), pp. 173-235, Dordrecht-Boston-London, Kluwer Academic Publishers. 
BASTIAENS J., DEFORCE K., KLINCK B., MEERSSCHAERT L., VERBRUGGEN C. \& VRYDAGHS L. (2005), « Palaeobotanical analyses », in CROMBÉ Ph. (ed.), The Last Hunter-Gatherer-Fishermen in Sandy Flanders (NW Belgium). The Verrebroek and Doel Excavation Projects (Vol. I: Palaeo-environment, chronology and features), Archaeological Reports Ghent University 3, pp. 251-278, Gent, Academia Press.

BEHRE K.-E. (1986), Anthropogenic Indicators in Pollen Diagrams, Rotterdam, Balkema.

BEYENS L. (1984), « Palynological and radiometric evidence for an early start of the Neolothicum in the Belgian Campine », Notae Praehistoricae 4, pp. 89-95.

CASPARIE W.A. \& STREEFKERK J.G. (1992), « Climatological, stratigraphic and palaeo-ecological aspects of mire development ", in VERHOEVEN J.T.A. (ed), Fens and Bogs in the Netherlands: Vegetation, History, Nutrient Dynamics and Conservation (Geobotany 18), pp. 81-129, DordrechtBoston-London, Kluwer Academic Publishers.

CROMBÉ PH., PERDAEN Y. \& SERGANT J. (2005), « Archaeological description », in CROMBÉ Ph. (ed), The Last Hunter-Gatherer-Fishermen in Sandy Flanders (NW Belgium). The Verrebroek and Doel Excavation Projects (Vol. I: Palaeo-environment, chronology and features), Archaeological Reports Ghent University 3, 141-179, Gent, Academia Press.

DENYS L. \& VERBRUGGEN C. (1989), «A case of drowning- The end of the Subatlantic peat growth and related palaeoenvironmental changes in the Lower Scheldt Basin (Belgium) based on diatom and pollen analysis ", Review of Palaeobotany and Palynology 59, pp. 7-36, Amsterdam, Elsevier.

DE PLOEY J. (1961), « Morfologie en Kwartair-stratigrafie van de Antwerpse Noorderkempen », Acta Geographica Lovaniensia 1, Leuven, Katholieke Universiteit Leuven.

FAEGRI K., KALAND P.E. \& KRZYWINSKI K. (1989), Textbook of Pollen Analysis by Knut Faegri and Johs. Iversen, IV edition, Chichester, John Wiley and sons, Ltd.

GODWIN H. (1968), « Terneuzen and buried forests of the East Anglian Fenland », New Phytologist 67, pp. 733-738, Blackwell.

GOTTSCHALK M.K.E. (1971), Stormvloeden en rivieroverstromingen in Nederland I, Assen, Van Gorcum \& Companie N.V.

HAVINGA A.J. (1984), « A 20-year experimental investigation into the differential corrosion susceptibility of pollen and spores in various soil types ", Pollen et Spores 26 (3-4), pp. 541-558.

JANSSEN C.R. (1974), Verkenningen in de palynologie, Utrecht, Oosthoek, Scheltema en Holkema.

JANSSENS W. \& FERGUSON D.K. (1985), « The palaeoecology of the Holocene sediments at Kallo, Northern Belgium », Review of Palaeobotany and Palynology 46, pp. 81-95, Amsterdam, Elsevier.

KRAMMER K. \& LANGE-BERTALOT H. (1997), Bacillariophyceae 1. Teil : Naviculaceae, Gustav Fischer Verlag.

KUYLENSTIERNA M. (1989), Benthic algal Vegetation in the Nordre Älv Estuary (Swedish West Coast) : Göteborg. Department of Marine Botany, University of Sweden.

LAMBINON J., DE LANGHE J.-E., DELVOSALLE L. \& DUVIGNEAUD J. (eds) (1998), Flora van België, het Groothertogdom Luxemburg, Noord-Frankrijk en de aangrenzende gebieden (Pteridofyten en Spermatofyten), Meise, Nationale Plantentuin.

MINNAERT G. \& VERBRUGGEN C. (1986), « Palynologisch onderzoek van een veenprofiel uit het Doeldok te Doel », Buitengewone Uitgaven van de Koninklijke Oudheidkundige Kring van het Land van Waas, 19 (Bijdragen van de Archaeologische Dienst Waasland I), pp. 201-208, Sint-Niklaas, Archeologische Dienst Waasland. 
MOORE P.D., WEBB J.A. \& COLLINSON M.E. (1991), Pollen analysis, 2nd edition, London, Blackwell. MUNAUT A.V. (1967a), Recherches paléo-écologiques en Basse et Moyenne Belgique (Acta Geographica Lovaniensia 6), Louvain, Université Catholique de Louvain.

MUNAUT A.V. (1967b), « Etude paléo-écologique d'un gisement tourbeux situé à Terneuzen (Pays-Bas)», Berichten Rijksdienst voor Oudheidkundig Bodemonderzoek, 17, pp. 7-28, Amersfoort, ROB.

PONS L.J. (1992), « Holocene peat formation in the lower parts of the Netherlands », in VERHOEVEN J.T.A. (ed), Fens and Bogs in the Netherlands: Vegetation, History, Nutrient Dynamics and Conservation (Geobotany 18), pp. 7-79, Dordrecht-Boston-London, Kluwer Academic Publishers.

PALS J.P., VAN GEEL B. \& DELFOS A. (1980), « Palaeoecological studies in the Klokkeweel bog near Hoogkarspel (Noord-Holland) », Review of Palaeobotany and Palynology, 30, pp. 371-418, Amsterdam, Elsevier.

PUNT W. (1976), Northwest European Pollen Flora, I, Amsterdam, Elsevier.

PUNT W. \& BLACKMORE S. (1991), Northwest European Pollen Flora, VI, Amsterdam, Elsevier.

PUNT W., BLACKMORE S. \& CLARKE G.C.S. (1988), Northwest European Pollen Flora, V, Amsterdam, Elsevier.

PUNT W. \& CLARKE G.C.S. (1980), Northwest European Pollen Flora, II, Amsterdam, Elsevier.

PUNT W. \& CLARKE G.C.S. (1981), Northwest European Pollen Flora, III, Amsterdam, Elsevier.

PUNT W. \& CLARKE G.C.S. (1984), Northwest European Pollen Flora, IV, Amsterdam, Elsevier.

PUNT W., BLACKMORE S. \& HOEN P.P. (1995), Northwest European Pollen Flora, VII, Amsterdam, Elsevier.

PUNT W., BLACKMORE S., HOEN P.P. \& STAFFORD P.J. (2003), Northwest European Pollen Flora, VIII, Amsterdam, Elsevier.

SABBE K. (1997), Systematics and ecology of intertidal benthic diatoms of the Westerschelde estuary (The Netherlands). Ongepubliceerde doctoraatsverhandeling, Universiteit Gent.

VAN BEURDEN L. (1999), « Vegetatieontwikkeling en landgebruik vanaf het Laat-Mesolithicum tot in de Middeleeuwen in de omgeving van 's-Hertogenbosch ", in FOKKENS H. \& JANSEN R. (red.), 2000 jaar bewoningsdynamiek. Brons- en ijzertijdbewoning in het Maas-Demer-Scheldegebied, pp. 271-285, Leiden, Faculteit der Archeologie-Universiteit Leiden.

VAN GEEL B. (1976), A palaeoecological study of holocene peat bog sections, based on the analysis of pollen, spores and macro and microscopic remains of fungi, algae, cormophytes and animals (Academisch proefschrift), Amsterdam, Universiteit van Amsterdam.

VAN GEEL B. \& APTROOT A. (2006), « Fossil ascomycetes in Quaternary deposits, Nova Hedwigia 82, 3-4, pp. 313-329.

VAN GEEL B., BOHNCKE S.J.P. \& DEE H. (1981), « A palaeoecological study of an upper Late Glacial and Holocene sequence from "De Borchert", The Netherlands ", Review of Palaeobotany and Palynology, 31, pp. 367-448, Amsterdam, Elsevier.

VAN GEEL B., KLINK A.G., PALS J.P. \& WIEGERS J. (1986), « An Upper Eemiaan lake deposit from Twente, eastern Netherlands ", Review of Palaeobotany and Palynology, 47, pp. 31-61, Amsterdam, Elsevier.

VAN GEEL B., BUURMAN J. \& WATERBOLK H.T. (1996), « Archaeological and palaeoecological indications of an abrupt climate change in the Netherlands, and evidence for climatological 
teleconnections around 2650 BP ", Journal of Quaternary Science, 11, 6, pp. 451-460, Chichester, John Wiley and sons, Ltd.

VAN GEEL B., RASPOPOV O.M., VAN DER PLICHT J., RENSSEN H. (1998), « Solar forcing of Abrupt Climate Change around 850 Calendar Years BC », in PEISER B.J., PALMER T. \& BAILEY M.E. (eds.), Natural catastrophes during Bronze Age civilisations, BAR International Series 728, pp. 162-168, Oxford, Tempus Reparatum.

VAN GEEL B., RENSSEN H. (1998), « Abrupt Climate Change around 2,650 BP in North-West Europe: Evidence for Climatic Teleconnections and a Tentative Explanation », in ISSAR A.S. \& BROWN N. (eds.), Water, Environment and Society in Times of Climatic Change, pp. 21-41, Dordrecht, Kluwer Academic Publishers.

VAN GEEL B. (2001), « Non-pollen palynomorphs », in SMOL J.P., BIRKS H.J.B. \& LAST W.M. (eds), Tracking Environmental Change Using Lake Sediments, Terrestrial, algal and silicaceous indicators vol. 3 , pp. 99-119, Dordrecht-Boston-London, Kluwer Academic Publishers.

VAN GEEL B., BUURMAN J., BRINKKEMPER O., SCHELVIS J., APTROOT A., VAN REENEN G. \& HAKBIJL T. (2003), « Environmental reconstruction of a Roman Period settlement site in Uitgeest (The Netherlands), with special reference to coprophilous fungi ", Journal of Archaeological Science, 30, 7, pp. 873-883, Amsterdam-Orlando, Elsevier.

VAN ROEYEN J.-P., MINNAERT G., VAN STRYDONCK M. \& VERBRUGGEN C. (1991), « Melsele-Hof ten Damme : prehistorische bewoning, landschappelijke ontwikkeling en kronologisch kader », Notae Praehistoricae, 11, pp. 41-49, Gent.

VAN ROEYEN J.-P., VERBRUGGEN C., KLINCK B. \& MEERSSCHAERT L. (2001), « Het Deurganckdok te Doel (Beveren, O.-Vl.). Paleolandschappelijk en archeologisch onderzoek », Annalen van de Koninklijke Oudheidkundige Kring van het Land van Waas 104 (Bijdragen van de Archeologische Dienst Waasland 5), pp. 437-484, Sint-Niklaas, Archeologische Dienst Waasland.

VAN STRYDONCK M., « Radiocarbon dating », in CROMBÉ Ph. (ed), The Last Hunter-GathererFishermen in Sandy Flanders (NW Belgium). The Verrebroek and Doel Excavation Projects (Vol. I: Palaeoenvironment, chronology and features), Archaeological Reports Ghent University, 3, pp. 127-137, Gent, Academia Press.

VERBRUGGEN C. (1999), «Quaternary palaeobotanical evolution of Northern Belgium », Geologica Belgica, 2, 3-4, pp. 99-110, Brussel, Belgische Vereniging voor Geologie.

VERBRUGGEN C. \& DENYS L. (1995), « Early tidal influence on the Lower Schelde, Belgium », in GULLENTOPS F. (ed), Wetlands in Flanders, Contributions to Palaeohydrology of the temperate Zone in the Last 15000 years (Aardkundige Mededelingen 6), Leuven, Katholieke Universiteit Leuven.

VERBRUGGEN C., DENYS L. \& KIDEN P. (1991), « Paleo-ecologische en geomorfologische evolutie van Laag- en Midden-België tijdens het Laat-Kwartair », De Aardrijkskunde, 3, pp. 357-376, Heverlee, Vereniging Leraren Aardrijkskunde.

VERBRUGGEN C., DENYS L. \& KIDEN P. (1996), « Belgium », in BERGLUND B.E., BIRKS H.J.B., RALSKA-JASIEWICZOWA M., WRIGHT H.E. (eds), Palaeoecological Events During the Last 15000 Years: Regional Syntheses of Palaeoecological Studies of Lakes and Mires in Europe, pp. 553-574, Chichester, John Wiley and Sons Ltd.

VERBRUGGEN C. \& SEMEY J. (1993), « Venen en moeren. Fysisch-geografische benadering », in DE KRAKER A.M.J., DE SMET M.E.E. \& VAN ROYEN H. (eds.), Over den Vier Ambachten, 750 jaar keure, 500 jaar Graaf Jansdijk, pp. 61-65, Kloosterzande, Deurinck. 
VOS P.C. \& VAN HEERINGEN R.M. (1997), « Holocene geology and occupation history of the Province of Zeeland (SW Netherlands) », in FISCHER M.M., Holocene evolution of Zeeland (SW Netherlands), Haarlem, Boom-Planeta.

WALLER M. (1994), The Fenland Project, Number 9: Flandrian Environmental Change in Fenland (East Anglian Archaeology 70), Cambridge, University of East Anglia.

WEEDA E.J., WESTRA R., WESTRA CH. \& WESTRA T. (1985), Nederlandse Ecologische Flora. Wilde planten en hun relaties, deel 1, Amsterdam, IVN.

WEEDA E.J., WESTRA R., WESTRA CH. \& WESTRA T. (1994), Nederlandse Ecologische Flora. Wilde planten en hun relaties, deel 5, Amsterdam, IVN.

ZAGWIJN W.H. \& VAN STAALDUINEN C.J (1975), Toelichting bij geologische overzichtskaarten van Nederland, Rijks Geologische Dienst Haarlem.

\section{ANNEXES}

\section{Pollenanalyse}

Bomen en struiken

Acer campestre type (esdoorn)

Alnus (els)

Betula (berk)

Carpinus betulus (haagbeuk)

Corylus avellana (hazelaar)

Fagus sylvatica (beuk)

Frangula alnus (sporkehout)

Fraxinus (es)

Hedera helix (klimop)

Ilex aquifolium (hulst)

Lonicera (kamperfoelie)

Myrica gale (gagel)

Picea (spar)

Pinus (den)

Populus (populier)

Quercus (eik)

Rhamnus catharticus (wegedoorn)

Salix (wilg)

Taxus baccata (taxus)

Tilia (linde)

Ulmus (olm)

Viburnum lantana (wollige sneeuwbal)

Viburnum opulus type (Gelderse roos type)

Viscum album (maretak)

Cultuurgewassen 
Cerealia type (graan type)

Secale cereale (rogge)

\section{Kruiden}

Anthemis type (schubkamille type)

Apiaceae (schermbloemenfamilie)

Armeria (engels gras)

Artemisia (bijvoet)

Aster type (aster type)

Brassicaceae (kruisbloemenfamilie)

Cannabis type (hennep type)

Caryophyllaceae (anjerfamilie)

Centaurea cyanus (korenbloem)

Centaurea nigra type (zwart knoopkruid type)

Chenopodiaceae (ganzevoetfamilie)

Cirsium (vederdistel)

Cladium mariscus (galigaan)

Compositae Liguliflorae (composietenfamilie-lintbloemigen)

Compositae Tubuliflorae ind. (composietenfamilie-buisbloemigen ind.)

Cyperaceae ind. (cypergrassen ind.)

Empetrum nigrum (kraaihei)

Ericaceae ind. (heide ind.)

Fallopia convolvulus (zwaluwtong)

Filipendula (spirea)

Galium type (walstro type)

Malva type (kaasjeskruid type)

Mentha type (munt type)

Papaver rhoeas type (grote klaproos type)

Plantago lanceolata (smalle weegbree)

Plantago major (grote weegbree)

Plantago maritima type (zeeweegbree type)

Poaceae (grassen)

Polygonum aviculare type (varkensgras type)

Polygonum persicaria type (perzikkruid type)

Ranunculus type (ranonkel type)

Rosaceae (rozenfamilie)

Rumex acetosa type (veldzuring type)

Rumex acetosella type (schapezuring type)

Rumex obtusifolius type (ridderzuring type)

Serratula type (zaagblad type)

Solanum dulcamara (bitterzoet)

Spergula type (spurrie type)

Succisa pratensis (blauwe knoop)

Urtica (brandnetel)

Valeriana dioica (kleine valeriaan)

Valeriana officinalis type (echte valeriaan type)

Valerianella (veldsla) 
Vicia type (wikke type)

Xanthium strumarium (late stekelnoot)

Oever- en Waterplanten

Callitriche (sterrenkroos)

Hydrocotyle vulgaris (waternavel)

Lysimachia vulgaris type (grote wederik type)

Lythrum salicaria (grote kattestaart)

Menyanthes trifoliata (waterdrieblad)

Nuphar (plomp)

Potamogeton (fonteinkruid)

Sparganium emersum type (kleine egelskop type)

Sparganium erectum type (grote egelskop type)

Typha latifolia (grote lisdodde),

\section{Varens en mossen}

Anthoceros punctatus type (zwart hauwmos type)

Equisetum (paardestaart)

Osmunda regalis (koningsvaren)

Polypodium vulgare (eikvaren)

Sphagnum (veenmos)

Thelypteris palustris (moerasvaren)

\section{Algen}

Botryoccocus colony (Type 901)

Closterium idiosporum (Type 60)

Pediastrum colony (Type 900)

Mougeotia sp. (Type 313)

Spirogyra sp. (psilate, type 130)

Spirogyra sp. (reticulate, type 132)

Zygnema type (Type 314)

Coprofiele fungi

Cercophora sp. (Type 112)

Podospora sp. (Type 466)

Sordaria sp. (Type 55A)

Sordaria sp. (Type 55B)

Andere fungi

Bactrodesmium type (Type 502)

cf. Clasterosporium caricinum (Type 25)

Culcitalna achraspora (Type 707) 
Glomus sp. (Type 207)

Diporotheca rhizophila (Type 143)

Meliola ellisii (Type 14)

Tilletia sphagni (Type 27)

Tetraploa aristata (Type 89)

Type 18

Type 23

Type 140

Type 148

Type 201

Ustulina deusta (Type 44)

Invertebraten

Amphitrema flavum (Type 31)

Hyalosphaenia subflava (Type 46)

Trichuris sp. (Type 531)

Type 180

Type 186

Varia

Cymatiosphaera (Type 116)

Juncus zaadfragment

Type 114

Type 128A

Type $128 \mathrm{~B}$

Type 547

\section{Zaden- en vruchtenonderzoek}

Alisma sp. (waterweegbree)

Alnus glutinosa (zwarte els)

Andromeda polifolia (lavendelhei)

Betula alba/pendula (ruwe en/of zachte berk)

Calluna vulgaris (struikhei)

Carex (zegge)

Cicuta virosa (gevlekte waterscheerling)

Cladium mariscus (galigaan)

Cornus sanguinea (rode kornoelje)

Erica tetralix (dopheide)

Lychnis flos-cuculi (echte koekoeksbloem)

Lycopus europaeus (wolfspoot)

Menyanthes trifoliata (waterdrieblad)

Nuphar lutea (gele plomp)

Oenanthe aquatica (watertorkruid)

Poaceae sp. (grassen)

Ranunculus lingua (grote boterbloem) 
Salix sp. (wilg)

Solanum dulcamara (bitterzoet)

Spagnum sp. (veenmos)

Urtica dioica (grote brandnetel)

\section{NOTES}

1. Aangezien sporen- en waterplanten, mossen en non-pollen palynomorfen in degelijk milieu lokaal oververtegenwoordigd kunnen zijn, werden ze niet tot de pollensom gerekend.

\section{RÉSUMÉS}

De graafwerken van een getijdendok op de linkeroever van de Schelde nabij Doel (België) boden een uitstekende gelegenheid om de stratigrafie en de paleo-ecologie van Holocene afzettingen in de Beneden Scheldepolders te bestuderen. Een complete organische sequentie, gedateerd tussen 6000 en $1400 \mathrm{BP}$, werd op basis van pollen, sporen en andere microfossielen, macroresten en diatomeeën onderzocht. Naast een volledig goed ontwikkelde representatieve botanische evolutie vanaf het Atlanticum werd ook belangrijke informatie verzameld over twee specifieke gebeurtenissen. Enderzijds kon de uitbreiding en de paleo-ecologische omstandigheden van de late Calais inundatie, tussen 5800 en 5000 BP, worden gereconstrueerd. Anderzijds werd het mogelijk om een beter inzicht te verwerven over de tijdspanne tussen het einde van de veengroei rond de $6^{\text {de }}-7^{\text {de }}$ eeuw $A D$ en de grote strategische overstromingen na $1580 \mathrm{AD}$. Een periode van non-depositie, gevolgd door lokale afzettingen van laatmiddeleeuwse strategische stormvloeden werd namelijk geattesteerd.

The excavations of a huge tidal dock on the left bank of the Scheldt river near Doel (Belgium) provided an excellent opportunity for the study of the stratigraphy and palaeoecology of the Holocene deposits in the Lower Scheldt polders. A complete organic sequence from the period between 6000 and $1400 \mathrm{BP}$ was radiocarbon dated and investigated by means of pollen, spores and other microfossils, macroremains and diatoms. Besides a good developed sequence of the botanical evolution since the Atlanticum, interesting information on two specific events was obtained. Firstly the extension and conditions of the late Calais inundation, between 5800 and 5000 BP could be reconstructed. Secondly it became possible to gain more insight in the timespan between the end of the peat growth around the $6^{\text {th }}-7^{\text {th }}$ century $\mathrm{AD}$ and the large strategic inundation after $1580 \mathrm{AD}$. A period of non deposition followed by local deposits of late medieval military storm surges could be recognised.

\section{INDEX}

Keywords : palaeo-ecology, peat sequence, Holocene, Lower Scheldt polders

Trefwoorden paleo-ecologie, veensequentie, Holoceen, Beneden Scheldepolders 


\section{AUTEURS}

\section{VANESSA GELORINI}

Universiteit Gent, Vanessa.Gelorini@UGent.be

\section{LIESELOTTE MEERSSCHAERT}

Archeologische Dienst Waasland, lmeersschaert@gmail.com

\section{ELIE VERLEYEN}

Universiteit Gent, Elie.Verleyen@UGent.be

CYRIEL VERBRUGGEN

Universiteit Gent, Cyriel.Verbruggen@UGent.be 